\title{
Relationship between metabolic syndrome and epicardial fat tissue thickness in patients with chronic obstructive pulmonary disease
}

\author{
Melike Demir, Halit Acet*, Halide Kaya, Mahsuk Taylan, Murat Yüksel*, \\ Süreyya Yılmaz, Cengizhan Sezgi, Gülistan Karadeniz¹, Derya Yenibertiz² \\ Departments of Chest Disease, *Cardiology, Faculty of Medicine, Dicle University, Diyarbakır-Turkey \\ ${ }^{1}$ Department of Chest Disease, Faculty of Medicine, Şifa University, İzmir-Turkey \\ ${ }^{2}$ Department of Chest Disease, Dr. Abdurrahman Yurtaslan Ankara Oncology Training and Research Hospital, Ankara-Turkey
}

\section{ABSTRACT}

Objective: An increase in epicardial fat tissue (EFT) thickness was found to be associated with metabolic syndrome (MS) and ischemic heart disease. MS is a comorbidity of chronic obstructive pulmonary disease (COPD) resulting from the accompanying systemic inflammation. The aim of our study was to investigate the usefulness of EFT thickness to predict MS in COPD patients.

Methods: COPD patients admitted to our clinic during January-December 2014 and healthy controls were included in this prospective casecontrol study. Patients with comorbidities, COPD exacerbation, and malignancies were excluded. Patients and controls were compared in terms of anthropometric measurements, MS-related examination and laboratory findings, pulmonary function tests, and EFT thickness. The correlations between EFT thickness and markers of MS in COPD were evaluated using the Student's t-test and logistic regression analysis.

Results: COPD patients and controls were composed of 82 and 84 individuals, respectively. MS was diagnosed in 31 (37.8\%) COPD patients. The EFT thickness was significantly higher in COPD patients than in the controls and was also higher in COPD patients with MS than in those without MS (all $p<0.001$ ). Each 1-mm increment of EFT raised the risk of MS two-fold ( $\mathrm{p}=0.011,0 \mathrm{R}=2.08,95 \% \mathrm{Cl}$ : 1.18-3.68). Increase in triglyceride level $(p=0.004,0 R=1.02,95 \% \mathrm{Cl}: 1.01-1.03)$ and reduction in forced vital capacity $(\mathrm{p}=0.025,0 \mathrm{R}=0.26,95 \% \mathrm{Cl}: 0.08-0.84)$ were found to be associated with increased MS risk. The cut-off value for EFT thickness in the prediction of MS in COPD patients was $6.75 \mathrm{~mm}$ (sensitivity: $83 \%$, specificity: $65 \%$ ). Conclusion: EFT thickness is a non-invasive and easily available parameter, which is valuable in the prediction of increased MS risk in COPD patients. Early diagnosis of patients at risk of MS may help to prevent ischemic heart disease in these patients. (Anatol J Cardiol 2016; 16:000-00) Keywords: COPD, epicardial fat tissue, metabolic syndrome

\section{Introduction}

Chronic obstructive pulmonary disease (COPD) is characterized by chronic inflammation of the airways as a result of longterm exposure to inhaled irritants such as tobacco smoke (1). It has been shown that the inflammatory response in COPD is not limited to the lungs, but also leads to a systemic inflammatory state in the body (2). Several systemic inflammatory markers or cytokines have been proposed to be related with COPD morbidity, mortality, COPD exacerbations, and decrement of lung functions (3). Patients with COPD frequently encounter systemic comorbid conditions, including hypertension, diabetes mellitus (DM), and cardiovascular diseases (CVDs) due to underlying systemic inflammatory status (4).

Metabolic syndrome (MS) is a clinical entity characterized by metabolic abnormalities, including abdominal obesity, high blood pressure, hyperglycemia, low high-density lipoprotein (HDL)cholesterol levels, and high triglyceride levels. MS is an important risk factor for CVD and type 2 DM (5). It has been shown that MS accompanies a number of inflammatory disorders such as rheumatoid arthritis (6) and systemic lupus erythematosus (7). Co-morbid conditions result in increases in the morbidity and mortality of MS patients. The relationship between COPD and MS has been studied previously $(2,8)$. These studies have shown that the vast majority of COPD patients have one or more components of MS and that co-existing MS is associated with higher levels of systemic inflammation. Systemic inflammation plays a key role in both COPD and MS, but the real inflammatory profile of these patients remains uncertain (4). Epicardial fat tissue (EFT) is a component of total visceral fat located on the heart surface between the myocardium and visceral layer

Address for correspondence: Dr. Melike Demir, Dicle Üniversitesi Tıp Fakültesi, Göğüs Hastalıkları Anabilim Dalı, Sur / Diyarbakır-Türkiye

Phone: +90 4122488001 Fax: +90 4122488240 E-mail: melikedoktor@hotmail.com

Accepted Date: 30.11.2015 Available Online Date: 10.02.2016

(C) Copyright 2016 by Turkish Society of Cardiology - Available online at www.anatoljcardiol.com DOI:10.14744/AnatolJCardiol.2016.6566 
of epicardium that serves as a source of several endocrine and inflammatory mediators (9). Epicardial fat has been proposed to play a pivotal role in the development of atherosclerosis and to be associated with unfavorable cardiovascular and metabolic risk profiles in human beings (10-12).

Previous studies have evaluated EFT in patients with either COPD or MS separately. We aimed to evaluate EFT in COPD patients with and without MS and to explore the predictive role of $\mathrm{EFT}$ in determining the presence of MS in COPD patients.

\section{Methods}

\section{Study design}

Patients with stable COPD (stage I-IV) who were admitted to our pulmonary diseases outpatient clinic during JanuaryDecember 2014 were included in this prospective case-control study. The study population was selected from 1280 individuals above 40 years of age with or without COPD. Pulmonary function tests were performed on all selected patients. Of the patients, 214 had COPD and 1066 had other conditions. Of these non-COPD patients, 821 were excluded from the study because of their comorbidities and 161 patients of the remaining 245 were excluded from the study because they were diagnosed with MS. Among the COPD patients, 130 were excluded from the study because of their additional diseases and 82 remaining COPD patients were investigated for the presence of MS.

A total of 82 patients with COPD formed the study group and 84 age- and gender-matched healthy subjects were recruited as the control group. Diagnosis of COPD was established according to the GOLD (The Global Initiative for Chronic Obstructive Lung Disease) criteria (13). The patients, who were free of respiratory tract infection and any acute exacerbation for the last 4 weeks prior to the recruitment, were categorized into GOLD stages I-IV. Patients over 40 years of age admitted to our outpatient clinic for non-specific chest pain or cough complaints and found as normal following clinical and laboratory evaluation, including pulmonary function tests, constituted the control group. Patients and controls with malignancy, DM, dyslipidemia, moderate-to-severe valvular heart disease, arrhythmias, cor pulmonale, inflammatory or infectious diseases, cerebrovascular disorders, renal or hepatic failure, and other accompanying diseases were excluded from the study. Patients having any respiratory disorder other than COPD were also excluded. All our patients were examined by the same cardiology specialist. Anamnesis, family histories, electrocardiography, and echocardiography of patients were evaluated. Eighty patients were excluded from the study because of low echogenity. In addition, patients who had a previous diagnosis of ischemic heart disease (IHD), who had ischemic electrocardiographic changes, who had segmental wall motion abnormalities of the left ventricle on echocardiography, who had cardiac arrest in their medical history, or who had class III-IV angina pectoris according to the Canada classification were excluded from the study because of the possible presence of IHD. Patients who had previously been hospitalized with cardiac failure and patients defined as class III-IV according to the New York Heart Association (NYHA) classification, i.e., who were thought to have cardiac failure, were excluded from the study. The drugs used by the patients were noted. Patients who were using beta blockers, angiotensin-converting enzyme (ACE) inhibitors, statins, oral antidiabetics, calcium channel blockers, or systemic steroids were not included in the study.

Demographic features, medical history, the modified Medical Research Council (mMRC) dyspnea scale, and smoking status of the study population were recorded. Smoking status was evaluated in three categories according to the definition by Centers for Disease Control and Prevention (CDC): current smoker, former smoker, and those who never smoked (14).

\section{Anthropometric measurements}

The height and weight of the study population were measured in light indoor clothes and without shoes, and body mass index (BMI) of each participant was calculated. The study population was categorized according to BMI as follows: underweight (BMI<18.5); normal (BMI: 18.5-24.9); overweight (BMI: 25.0-29.9); and obese (BMI $\geq 30.0$ ). Waist circumference was calculated by a single researcher using a measuring tape over the unclothed abdomen, with measurements made halfway between the lower border of the ribs and the highest point of iliac crest (at the umbilicus level) in the standing position (15).

\section{Blood pressure measurement}

Systolic and diastolic blood pressures were measured by a digital sphygmomanometer (Omron M2 Compact, Omron, Japan) after 10 minutes of rest according to the American Heart Association's recommendations (16). The mean of the last three measurements was recorded.

\section{Biochemical analysis}

After fasting overnight, a venous blood sample $(10 \mathrm{~mL})$ was obtained. Total cholesterol, high density lipoprotein (HDL) cholesterol, low-density lipoprotein (LDL), triglycerides, glucose, and creatinine levels were measured with the Abbott Architect C16000 auto-analyzer (Abbott Park, Abbott Diagnostics, USA). Serum insulin was determined by a commercially available assay kit (Roche Cobas 6000, Roche-Hitachi Diagnostics, Germany). Insulin-resistance was estimated using the homeostasis model assessment as an index of insulin resistance (HOMA-IR), defined as follows: (fasting glucose $\mathrm{mg} / \mathrm{dL} \mathrm{x}$ fasting insulin $\mu \mathrm{U} / \mathrm{mL}$ ) / 405 (17). The cut-off value was taken as 2.7 for HOMA-IR (18). Hematologic parameters were measured by an automated hematology analyzer system (Abbott Cell-Dyn Ruby; Abbott Diagnostics, USA). Absolute cell counts were utilized to perform subsequent analyses. The serum concentration of $\mathrm{C}$-reactive protein was evaluated using the high-sensitivity immunochemistry system, the nephelometric method (Image 800, Beckman Coulter, USA). 


\section{Definition of metabolic syndrome}

MS was defined as abdominal obesity (a waist circumference of $\geq 94 \mathrm{~cm}$ for males and $\geq 80 \mathrm{~cm}$ for females) plus any two of the following criteria:

1. High blood pressure (>130/85 mm Hg);

2. Insulin resistance [fasting plasma glucose (FPG) $\geq 100 \mathrm{mg}$ ];

3. High triglyceride levels $(\geq 150 \mathrm{mg} / \mathrm{dL})$;

4. Low HDL cholesterol level $(<40 \mathrm{mg} / \mathrm{dL}$ for men, $<50 \mathrm{mg} / \mathrm{dL}$ for women) according to the International Diabetes Federation (IDF) criteria (5).

\section{Pulmonary function tests}

Pulmonary function parameters were collected using standardized spirometry (ZAN 300: ZAN Messgerate $\mathrm{GmbH}$, Oberthulba, Germany). The degree of severity of airflow limitation was classified according to the GOLD criteria (13).

\section{Measurement of the epicardial fat tissue}

EFT was measured by means of transthoracic echocardiography with a GE VIVID 7 (Horten, Norway) instrument according to standard techniques in accordance with the recommendations of the American Society of Echocardiography (19). EFT was measured on the free wall of the right ventricle at end-diastole from the parasternal long- and short-axis views by a cardiologist blinded to the clinical data. Measurements from the parasternal long- and short-axes were averaged (Fig. 1).

\section{Statistical analysis}

Normality was assessed using the Kolmogorov-Smirnov test. Data were compared between subject groups using analysis of variance (ANOVA) for parametric data and using the KruskalWallis test for non-parametric data. If a $p$-value of $<0.05$ was produced by ANOVA, then unpaired Student's t-tests for parametric data and Mann-Whitney $U$ tests for non-parametric data were used for pair-wise comparisons.

Binary logistic regression analysis was performed to evaluate independent predictive values of the following potential variables for the presence of MS in patients with COPD: EFT,

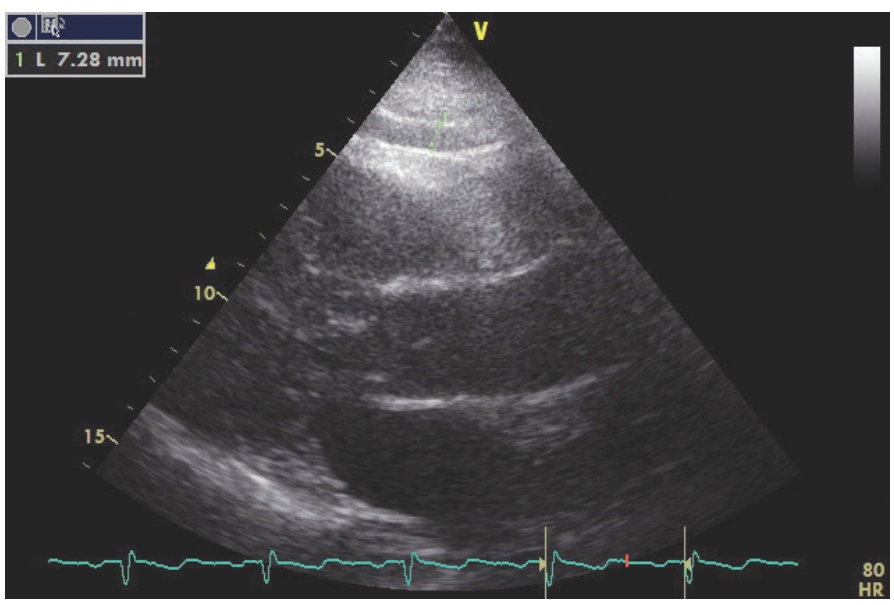

Figure 1. End-diastolic epicardial fat tissue thickness triglyceride, $\mathrm{HDL}$ cholesterol, glucose, creatinine, forced vital capacity (FVC), FEV1, COPD stage, COPD acute exacerbation/year, smoking states, BMI, gender, age, mean platelet volume (MPV), neutrophil count, lymphocyte count, platelet count, insulin resistance (HOMA-IR $\geq 2.7$ ), and insulin.

The receiver operating characteristics (ROC) curve was obtained for various parameters: EFT, glucose, triglyceride, FVC, and HDL cholesterol. Youden's index was calculated (Yl=sensitivity+specificity-1) for each coordinate point of the ROC curve to determine the cut-off value, which has the maximum sensitivity and specificity pair. A p-value of less than 0.05 was considered as statistically significant.

\section{Ethics statement}

This prospective study was approved by the Human-Research Review Board of Dicle University (Meeting Number: 22.01.2014 /103), and all participants gave written informed consent.

\section{Results}

\section{Characteristics of the study population}

The clinical and demographical characteristics of 82 COPD patients [57 (70\%) of which were male, with a mean age of $66 \pm 11$ years] and 84 age- and gender-matched healthy controls [63 $(75 \%)$ of whom were male, with a mean age of $60.0 \pm 9.6$ years] are presented in Table 1. The patient group was divided into two subgroups according to presence of MS: COPD patients with $(n=31)$ and without $(n=51)$ MS. The mean EFT $(p<0.001)$, insulin resistance $(p<0.001), \operatorname{MPV}(p=0.016)$, and smoker ratio $(p<0.001)$ were significantly higher in the patient group than in the healthy controls. HDL cholesterol was higher in the patients with both COPD and MS than in the control group $(p=0.030)$ and the COPD group $(p<0.001)$. The triglyceride levels were higher in the patients with both COPD and MS than in the control group ( $p=0.044$ ) and the COPD group $(p<0.001)$. The HOMA-IR was higher in the patients with COPD than in the control group $(p<0.001)$, and was higher in the patients with both COPD and MS than in the patients with COPD $(p<0.001)$. The glucose levels were higher in the patients with both COPD and MS than in the patients with COPD alone $(p=0.006)$.

\section{Subgroup analysis: patients with chronic obstructive pulmonary disease, with and without MS}

The COPD patients with MS had higher FPG, insulin, insulin resistance, EFT, triglyceride, and lower HDL cholesterol levels than did the COPD patients without MS (Table 1). The independent variables associated with the presence of MS in COPD patients [including EFT, triglyceride, HDL cholesterol, FPG, creatinine, FVC, FEV1, COPD stage, number of COPD exacerbation/ year, smoking status, BMI, gender, age, MPV, neutrophil count, lymphocyte count, platelet count, insulin, and insulin resistance (HOMA-IR $\geq 2.7)$ ] were assessed with a binary logistic regression analysis using a backward condition method and the method 
Table 1. The demographic and laboratory characteristics of the study groups

\begin{tabular}{|c|c|c|c|c|}
\hline & $\begin{array}{l}\text { Control } \\
\text { group } \\
(\mathrm{n}=84)\end{array}$ & $\begin{array}{l}\text { COPD } \\
\text { group } \\
(n=51)\end{array}$ & $\begin{array}{c}\text { COPD-MS } \\
\text { group } \\
(n=31)\end{array}$ & $P$ \\
\hline \multicolumn{5}{|l|}{ Demographic parameters } \\
\hline Age years $^{a}$ & $66.0 \pm 9.6$ & $66.0 \pm 10.9$ & $66.1 \pm 8.9$ & $0.08^{* *}$ \\
\hline $\begin{array}{l}\text { Gender, male/ } \\
\text { female, } n\end{array}$ & $63 / 21$ & $46 / 51$ & $21 / 10$ & $0.033 * * *$ \\
\hline $\mathrm{BMI}\left(\mathrm{kg} / \mathrm{m}^{2}\right)^{\mathrm{a}}$ & $29.7 \pm 5.4$ & $25.3 \pm 3.81$ & $28.7 \pm 4.7^{\prime \prime}$ & $<0.001^{* *}$ \\
\hline \multicolumn{5}{|l|}{ Smoking status } \\
\hline Smoker (n, \%) & 6 & 81 & 4 & $<0.001^{* * *}$ \\
\hline Pack-year $^{\mathrm{a}}$ & $15.5 \pm 14.6$ & $60.1 \pm 27.3^{1}$ & $59.9 \pm 26.3^{1}$ & $<0.001^{* *}$ \\
\hline \multicolumn{5}{|l|}{ Laboratory parameters } \\
\hline \multicolumn{5}{|l|}{ Metabolic syndrome } \\
\hline Glucose $(\mathrm{mg})^{\mathrm{a}}$ & $94.2 \pm 10.4$ & $89.4 \pm 13.1$ & $98.2 \pm 15.3^{\prime \prime}$ & $0.006^{* *}$ \\
\hline $\begin{array}{l}\text { HDL cholesterol } \\
(\mathrm{mg} / \mathrm{dL})^{\mathrm{a}}\end{array}$ & $49.1 \pm 13.1$ & $45.2 \pm 10.8$ & $38.1 \pm 10.5^{1,11}$ & $<0.001^{* *}$ \\
\hline Triglyceride $(\mathrm{mg} / \mathrm{dL})^{\mathrm{a}}$ & $139.6 \pm 62.5$ & $112.6 \pm 49.5^{\prime}$ & $181.7 \pm 82.2^{1,11}$ & $<0.001^{* *}$ \\
\hline $\mathrm{HT}(\mathrm{n})(\geq 130 / 85 \mathrm{~mm} \mathrm{Hg})$ & 34 & 21 & 24 & $0.001^{* *}$ \\
\hline \multicolumn{5}{|l|}{ Others } \\
\hline MPV (fL) ${ }^{\mathrm{a}}$ & $7.5 \pm 0.9$ & $8.1 \pm 1.5^{1}$ & $7.9 \pm 1.2$ & $<0.001^{* *}$ \\
\hline $\mathrm{CRP}(\mathrm{mg} / \mathrm{dL})^{\mathrm{a}}$ & $0.4 \pm 0.2$ & $0.5 \pm 0.3$ & $0.6 \pm 0.3^{1}$ & $<0.001^{* *}$ \\
\hline Insulin $(\mu \mathrm{U} / \mathrm{mL})^{\mathrm{a}}$ & $11.5 \pm 9.8$ & $15.2 \pm 14.4$ & $31.0 \pm 30.2^{1, \| 1}$ & $0.017^{* *}$ \\
\hline Homa-IR ${ }^{a}$ & $2.7 \pm 2.5$ & $3.4 \pm 3.4^{1}$ & $7.7 \pm 8.2^{11}$ & $0.036^{* *}$ \\
\hline \multicolumn{5}{|l|}{ Echocardiography } \\
\hline $\mathrm{EFT}(\mathrm{mm})^{\mathrm{a}}$ & $4.8 \pm 1.1$ & $6.1 \pm 0.9^{1}$ & $7.7 \pm 1.8^{\prime, 11}$ & $<0.001^{* *}$ \\
\hline \multicolumn{5}{|l|}{ Spirometry } \\
\hline FEV1 (L) ${ }^{\mathrm{a}}$ & $3.1 \pm 0.6$ & $1.6 \pm 0.6^{l}$ & $1.6 \pm 0.5^{\prime}$ & $<0.001^{* *}$ \\
\hline $\mathrm{FVC}(\mathrm{L})^{\mathrm{a}}$ & $3.8 \pm 0.8$ & $2.7 \pm 0.91$ & $2.2 \pm 0.6^{\prime}$ & $<0.001^{* *}$ \\
\hline FEV1/FVC $(\%)^{a}$ & $97.8 \pm 14.4$ & $57.9 \pm 7.9^{1}$ & $60.0 \pm 5.3^{1}$ & $<0.001^{* *}$ \\
\hline \multicolumn{5}{|c|}{$\begin{array}{l}\text { BMI - body mass index; COPD - chronic obstructive pulmonary disease; COPD-MS - } \\
\text { COPD patients with metabolic syndrome; CRP - C-reactive protein; EFT - epicardial fat } \\
\text { tissue; FEV1 - forced expiratory volume in } 1 \mathrm{~s} ; \mathrm{FVC} \text { - forced vital capacity; HDL cholesterol } \\
\text { - high-density lipoprotein; Homa-IR - homeostatic model assessment-insulin resistance; } \\
\text { HT - hypertension; MPV - mean platelet volume; I - control group; II -COPD group; III - } \\
\text { COPD-MS group } \\
\text { aMean } \pm \text { standard deviation. } \\
\text { **P is based on one-way ANOVA test. } \\
\text { ***P is based on chi-square test or Fisher's exact test as appropriate. } \\
\text { Groups with significant differences according to the posthoc Tukey's b test and Bonfer- } \\
\text { roni corrected Mann-Whitney U test is shown in superscript roman numerals }\end{array}$} \\
\hline
\end{tabular}

was found to be statistically significant $(R=0.475, p<0.001)$. The independent variables which predict the presence of MS are presented in Table 2. The risk of having MS in COPD patients was increased twice with each 1-mm increase in EFT ( $p=0.011$, $\mathrm{OR}=2.084,95 \% \mathrm{Cl}$ : 1.18-3.68). The risk of development of MS increased with increased serum triglycerides $(p=0.004, O R=1.020$, $95 \% \mathrm{Cl}: 1.01-1.03)$ and decreased FVC $(p=0.025,0 R=0.259$, $95 \%$ Cl: $0.08-0.84$ ) (Table 2). The mean FVC (\% predicted) was $82.5 \pm 20.9$ in patients with COPD and $59.3 \pm 11.9$ in those with MS
Table 2. Outcomes of the binary logistic regression analysis

\begin{tabular}{|l|c|c|c|c|c|}
\hline Variables & B & SE & Wald & $\boldsymbol{P}$ & OR (95\%CI) \\
\hline EFT & 0.734 & 0.290 & 6.428 & 0.011 & $2.084(1.18-3.68)$ \\
\hline Triglyceride & 0.020 & 0.007 & 8.420 & 0.004 & $1.020(1.01-1.03)$ \\
\hline FVC & -1.352 & 0.604 & 5.017 & 0.025 & $0.259(0.08-0.84)$ \\
\hline Constant & -5.412 & 2.407 & 5.056 & 0.025 & 0.004 \\
\hline $\begin{array}{l}\text { B - regression coefficient; EFT - epicardial fat tissue; FVC - forced vital capacity; OR } \\
\text { (95\% CI) - odds ratio with 95\% confidence interval; SE - standard error of regression } \\
\text { coefficient; Wald - the value of Wald statistics }\end{array}$
\end{tabular}

Table 3. The receiver operating characteristic curve results for various variables used in prediction of metabolic syndrome

\begin{tabular}{|c|c|c|c|c|}
\hline \multirow[t]{2}{*}{ Variables } & \multirow[t]{2}{*}{ AUC } & \multirow[t]{2}{*}{$P$} & \multicolumn{2}{|c|}{$95 \% \mathrm{CI}$} \\
\hline & & & Lower & Upper \\
\hline EFT & 0.788 & 0.000 & 0.635 & 0.941 \\
\hline Triglyceride & 0.762 & 0.002 & 0.628 & 0.896 \\
\hline Glucose & 0.712 & 0.010 & 0.568 & 0.856 \\
\hline FVC & 0.353 & 0.076 & 0.205 & 0.502 \\
\hline HDL cholesterol & 0.301 & 0.016 & 0.137 & 0.464 \\
\hline
\end{tabular}

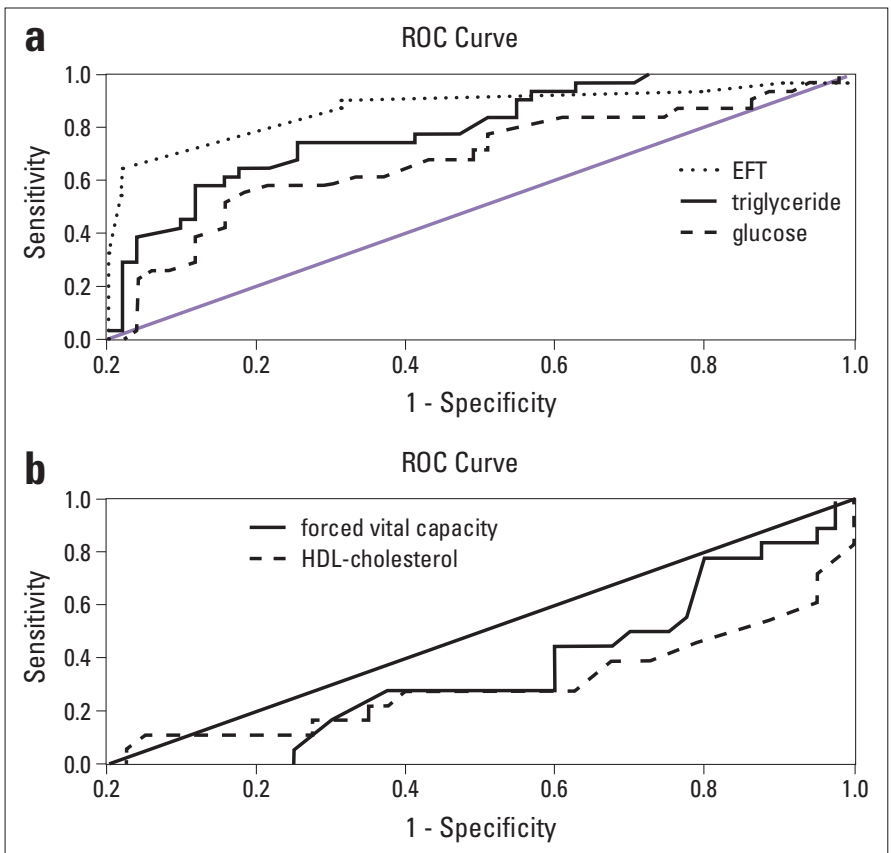

Figure 2. (a) The receiver operating characteristic curve constructed from epicardial fat tissue, glucose, and triglyceride measurements as a predictor of metabolic syndrome in patients with chronic obstructive pulmonary disease. (b) The receiver operating characteristic curve constructed from forced vital capacity and high-density lipoprotein cholesterol measurements as a predictor of metabolic syndrome in patients with chronic obstructive pulmonary disease

and COPD $(p<0.001)$. The mean serum triglyceride levels were $112.6 \pm 49.5 \mathrm{mg} / \mathrm{dL}$ in patients with COPD and $181.7 \pm 82.2 \mathrm{mg} / \mathrm{dL}$ in those with MS and COPD $(p<0.001)$. 
The ROC curve as a predictor of MS in patients with COPD was constructed from EFT, glucose, triglyceride, FVC, and HDL cholesterol measurements. In ROC curve analysis, the area under curve $(A U C)$ for EFT was $0.788(p<0.001)$ (Table 3 and Fig. $2 A$ and 2B). A cut-off of $6.75 \mathrm{~mm}$ of EFT predicted the presence of MS in COPD patients with a sensitivity of $83 \%$ and a specificity of $65 \%$.

\section{Discussion}

The main findings of the study were as follows: i) EFT was increased in patients with COPD compared to that in healthy individuals; ii) COPD patients with MS had a higher mean EFT value than those without MS did; iii) the multivariate logistic regression analysis revealed that an increase in EFT is associated with an increase in the risk of having MS in COPD patients; iv) an EFT value above $6.75 \mathrm{~mm}$ predicts the presence of MS in COPD patients with a sensitivity of $83 \%$ and a specificity of $65 \%$; and v) the patient group had significantly higher levels of insulin and insulin resistance than healthy controls did.

Smoking may trigger systemic inflammation and oxidative stress, which results in increased insulin resistance and DM (20). Patients with COPD due to smoking are considered to have higher levels of inflammation (8). Additionally, previous studies have shown that platelet functions are disrupted and MPV is increased because of hypoxia in COPD patients $(21,22)$. In one study, the levels of MPV were found to be higher in smokers than in non-smokers (23). Zhang et al. (24) detected higher MPV levels in COPD patients than in healthy subjects. In a similar study, it was shown that MPV increased during periods of both stable and acute exacerbation in COPD patients (25). Another study demonstrated increased MPV in patients with MS (26). We did not encounter any studies investigating MPV levels in COPD patients with MS. Our results showed no difference between MPV values of COPD patients with or without MS. The levels of MPV were higher in the COPD patients than in the control group, similar to the results of the studies mentioned above. Further studies recruiting higher number of subjects are needed to determine the impact of MPV levels in predicting MS in patients with COPD.

The inflammatory process occurring in COPD promotes the development of comorbidities by causing a systemic inflammatory response (4). Fat tissue developing in the epicardial area is a marker of this systemic response and can function as a lipidstorage depot, as an endocrine organ that secretes hormones, and as inflammatory tissue that secretes cytokines and chemokines (10). Various studies have shown EFT to increase in systemic inflammatory diseases such as RA (6), SLE (7), and Behçet's disease (27). There are very few studies in the literature investigating the association of COPD and EFT. One of these studies showed decreased EFT in patients with COPD (28), whereas the other showed the opposite (29). Our study showed increased EFT in patients with COPD compared to healthy controls. The increased values of EFT in the patient group are thought to be due to the fact that COPD is a systemic inflammatory disease.
Early diagnosis and treating co-morbid disorders may diminish the mortality rates of diseases with a chronic course such as COPD. Furthermore, CVDs are the most common cause of mortality in COPD patients. Presence of MS is one of the most important risk factors for IHD (30). In one study, an increase in the thickness of EFT was shown in IHD, a disease in which MS has been accepted to be a risk factor (31). Early detection and treatment of MS in patients with COPD will decrease the risk of IHD and subsequent mortality. We did not encounter any studies investigating the association of MS in COPD patients and EFT. We found that COPD patients with MS had increased EFT thickness relative to those without MS. Additionally, an EFT thickness of above 6.75 $\mathrm{mm}$ predicted MS in COPD patients with a sensitivity of $83 \%$ and a specificity of $65 \%$. This finding supports the conclusion that the presence of MS is linked with a further increase in EFT thickness in COPD patients. Used in the establishment of MS diagnosis are plasma glucose levels and presence of $\mathrm{HT}$, both of which might be influenced by corticosteroids used in COPD and these changes may last several days. However, an increase in the amount of EFT occurs slowly over a long period of time. Therefore, noninvasively measured EFT thickness may be valuable to estimate the presence of MS in COPD patients. Furthermore, we think that increased EFT detected in echocardiography during follow-up of COPD patients may be a useful parameter in predicting MS. Thus, the determination of MS beforehand in COPD patients may aid in prevention of the development of CVD. Currently, the measurement of EFT is not recommended in algorithms which determine risk factors. However, the significant parameters presented in this study are interesting enough to warrant further research. If EFT is intended to be used as a diagnostic tool for risk classification, it should be evaluated along with other risk factors.

There are studies showing decreased FVC in patients with MS (32-34) and an association between decreased FVC (L) and MS in a patient group (33). In a study recruiting 4001 adults, decreased FVC (L, \%) was shown to be associated with each metabolic risk factor (waist circumference, systolic blood pressure, and serum triglyceride level) and MS (35). Another study exploring MS prevalence in COPD patients according to the IDF criteria reported that MS is associated with physical inactivity independent of the presence and degree of airway obstruction (36). Another study showed no association of MS with FVC (mean FVC was $80.4 \%$ in COPD and $72.4 \%$ in MS and COPD) or FEV1 (mean FEV1 was $55.5 \%$ in COPD and $54.6 \%$ in MS and COPD) (37). No relation of FEV1 values to MS was detected in our study, whereas the FVC values were significantly lower in patients with MS and COPD (mean FVC was $82.5 \%$ in COPD and $59.3 \%$ in MS and COPD). We did not find any relationship between COPD stage, number of exacerbations/year, and number of hospitalizations/year and the presence of MS in COPD patients. We showed that a decrease in FVC $(\mathrm{L}, \%)$ has a predictive value for MS in COPD patients. The conditions causing restriction of pulmonary functions such as abdominal obesity, weakness in respiratory muscles, and physical inactivity can be considered as important risk factors for MS development in COPD, rather than the COPD grade. 


\section{Study limitations}

Our study has some limitations which should be kept in mind while interpreting the results. First, the number of females was relatively low in the study population. The main reason for this is that smokers are mostly male in our region; thus, COPD patients mostly consist of male individuals. Second, the relatively small sample size of our study limits making more precise interpretations. Exclusion of COPD patients having any of the exclusion criteria and enrolment of patients only during the stabilized period of COPD limited the study cohort. The cross-sectional design of the study is a further limitation. Another limitation of our study is that the inter-observer and intra-observer variabilities of EFT could not be calculated due to the working conditions of our hospital. All patients were evaluated by one cardiologist.

\section{Conclusion}

We found that EFT is thicker in COPD patients with MS than in those without MS and healthy controls. EFT, a cheap and practical method, can aid in determining MS in patients with COPD to predict the risk for cardiometabolic diseases in early the stages. Further studies recruiting higher numbers of subjects and evaluating emphysema and chronic bronchitis patients separately are needed to determine the exact association of EFT and MS in patients with COPD.

Conflict of interest: None declared.

Peer-review: Externally peer-reviewed.

Authorship contributions: Concept- M.D., M.T., H.A., S.Y.; DesignM.D., H.K., H.A.; Supervision-M.D., S.Y., G.K.; Funding-M.D., G.K.; Materials-H.A., M.D., M.Y., H.K.; Data collection \&/or processing-H.K., G.K., M.Y., D.Y.; Literature search-C.S., M.T.; Writing - C.S., M.T., G.K.; Critical review- C.S., S.Y., D.Y.

\section{References}

1. Barreiro $E$, Criner GJ. Update in chronic obstructive pulmonary disease 2013. Am J Respir Crit Care Med 2014; 189: 1337-44.

2. Garcia-Rio F, Miravitlles M, Soriano JB, Munoz L, Duran-Tauleria E, Sanchez G, et al. Systemic inflammation in chronic obstructive pulmonary disease: a population-based study. Respir Res 2010; 11: 63.

3. Agusti A, Edwards LD, Rennard SI, Mac Nee W, Tal-Singer R, Miller $\mathrm{BE}$, et al. Persistent systemic inflammation is associated with poor clinical outcomes in COPD: a novel phenotype. PLoS One 2012; 7: e37483.

4. Groenewegen KH, Postma DS, Hop WC, Wielders PL, Schlosser NJ, Wouters EF. Increased systemic inflammation is a risk factor for COPD exacerbations. Chest 2008; 133: 350-7.

5. Alberti KG, Zimmet P, Shaw J. Metabolic syndrome-a new worldwide definition. A Consensus Statement from the International Diabetes Federation. Diabet Med 2006; 23: 469-80.

6. Ormseth MJ, Lipson A, Alexopoulos N, Hartlage GR, Oeser AM, Bian A, et al. Association of epicardial adipose tissue with cardio- metabolic risk and metabolic syndrome in patients with rheumatoid arthritis. Arthritis Care Res (Hoboken) 2013; 65: 1410-5.

7. Lipson A, Alexopoulos N, Hartlage GR, Arepalli C, Oeser A, Bian A, et al. Epicardial adipose tissue is increased in patients with systemic lupus erythematosus. Atherosclerosis 2012; 223: 389-93.

8. Breyer MK, Spruit MA, Hanson CK, Franssen FM, Vanfleteren LE, Groenen MT, et al. Prevalence of metabolic syndrome in COPD patients and its consequences. PLoS One 2014; 9: e98013.

9. Iacobellis G, Corradi D, Sharma AM. Epicardial adipose tissue: anatomic, biomolecular and clinical relationships with the heart. Nat Clin Pract Cardiovasc Med 2005; 2: 536-43.

10. Pierdomenico SD, Pierdomenico AM, Cuccurullo F, lacobellis G. Meta-analysis of the relation of echocardiographic epicardial adipose tissue thickness and the metabolic syndrome. Am J Cardiol 2013; 111: 73-8.

11. Rabkin SW. The relationship between epicardial fat and indices of obesity and the metabolic syndrome: a systematic review and meta-analysis. Metab Syndr Relat Disord 2014; 12: 31-42.

12. Pezeshkian M, Mahtabipour MR. Epicardial and subcutaneous adipose tissue fatty acids profiles in diabetic and non-diabetic patients candidate for coronary artery bypass graft. Bioimpacts 2013; 3: 83-9.

13. Global Initiative for Chronic Obstructive Lung Disease. Global strategy for the diagnosis, management and prevention of chronic obstructive pulmonary disease. Updated 2014 [http://www.goldcopd. $\mathrm{com} /]$

14. Centers for Disease Control and Prevention(CDC). State-specific secondhand smoke exposure and current cigarette smoking among adults United States, 2008. MMWR Morb Mortal Wkly Rep 2009; 58: 1232-5.

15. Landbo C, Prescott E, Lange P, Vestbo J, Almdal TP. Prognostic value of nutritional status in chronic obstructive pulmonary disease. Am J Respir Crit Care Med 1999; 160: 1856-61.

16. Chobanian AV, Bakris GL, Black HR, Cushman WC, Green LA, Izzo $\mathrm{JL} J$ r, et al. The Seventh Report ofthe Joint National Committee on Prevention, Detection, Evaluation, and Treatment of High Blood Pressure: the JNC 7 report. JAMA 2003; 289: 2560-72.

17. Reilly MP, Wolfe ML, Rhodes T, Girman C, Mehta N, Rader DJ. Measures of insulin resistance add incremental value to the clinical diagnosis of metabolic syndrome in association with coronary atherosclerosis. Circulation 2004; 110: 803-9.

18. Topsakal S, Yerlikaya E, Akın F, Kaptanoğlu B, Erürker T. Relation with HOMA-IR and thyroid hormones in obese Turkish women with metabolic syndrome. Eat Weight Disord 2012; 17: 57-61.

19. Lang RM, Bierig M, Devereux RB, Flachskampf FA, Foster E, Pellikka PA, et al. Recommendations for chamber quantification: a report from the American Society of Echocardiography's Guidelines and Standards Committee and the Chamber Quantification Writing Group, developed in conjunction with the European Association of Echocardiography, a branch of the European Society of Cardiology. J Am Soc Echocardiogr 2005; 18: 1440-63.

20. Oğuz A, Temizhan A, Abacı A, Kozan O, Erol C, Öngen Z, et al. Obesity and abdominal obesity; an alarming challenge for cardio-metabolic risk in Turkish adults. Anadolu Kardiyol Derg 2008; 8: 401-6.

21. Steiropoulos P, Papanas N, Nena E, Xanthoudaki M, Goula T, Froudarakis $\mathrm{M}$, et al. Mean platelet volume and platelet distribution width in patients with chronic obstructive pulmonary disease: the role of comorbidities. Angiology 2013; 64: 535-9.

22. Ulaşlı SS, Özyürek BA, Yılmaz EB, Ulubay G. Mean platelet volume as an inflammatory marker in acute exacerbation of chronic ob- 
structive pulmonary disease. Pol Arch Med Wewn 2012; 122: 28490.

23. Cho SY, You E, Lee HJ, Lee WI, Park TS. Smoking cession decreases mean platelet volume in healthy Korean populations. Clin Lab 2014; 60: 1413-6.

24. Zhang M, Li Y, Zhang J, Zhang O, Yang X, Shan H, et al. Mean platelet volume is elevated in exacerbated and convalescent COPD patients. Clin Chim Acta 2015; 451: 227-31.

25. Maclay JD, McAllister DA, Johnston S, Raftis J, McGuinnes C, Deans $A$, et al. Increased platelet activation in patients with stable and acute exacerbation of COPD. Thorax 2011; 66: 769-74.

26. Farah R, Khamisy-Farah R. Significance of MPV, RDW with the presence and severity of metabolic syndrome. Exp Clin Endocrinol Diabetes 2015; 123: 567-70.

27. Taşolar H, Taşolar S, Kurtuluş D, Altun B, Bayramoğlu A, Otlu YÖ, et al. Increased epicardial adipose tissue thickness on transthoracic echocardiography in patients with Behçet disease. J Ultrasound Med 2014; 33: 1393-400.

28. Kaplan 0, Kurtoğlu E, Gözübüyük G, Doğan C, Acar Z, EyüpKoca F, et al. Epicardial adipose tissue thickness in patients with chronic obstructive pulmonary disease having right ventricular systolic dysfunction. Eur Rev Med Pharmacol Sci 2015; 19: 2461-7.

29. Zagaceta J, Zulueta JJ, Bastarrika G, Colina I, Alcaide AB, Campo $A$, et al. Epicardial adipose tissue in patients with chronic obstructive pulmonary disease. PLoS One 2013; 8: e65593.

30. Grundy SM. Metabolic syndrome: connecting and reconciling cardiovascular and diabetes worlds. J Am Coll Cardiol 2006; 47: 1093-
100.

31. Ding J, Hsu FC, Harris TB, Liu Y, Kritchevsky SB, Szklo M, et al. The association of pericardial fat with incident coronary heart disease: the Multi-Ethnic Study of Atherosclerosis (MESA). Am J Clin Nutr 2009; 90: 499-504.

32. Buchmann N, Norman K, Steinhagen-Thiessen E, Demuth I, Eckardt R. Pulmonary function in elderly subjects with metabolic syndrome and type II diabetes: Data from the Berlin Aging Study II. Z Gerontol Geriatr 2015 Oct 27. Epub ahead of print.

33. Chen YS, Li XO, Li HR, Yu XL, Lu FF, Huang LP, et al. Spirometric prediction equations and the relationship between metabolic syndrome and spirometric parameters from an island in Fujian, China. Clin Respir J 2015 Sep 14. Epub ahead of print.

34. Leone N, Courbon D, Thomas F, Bean K, Jégo B, Leynaert B, et al. Lung function impairment and metabolic syndrome the critical role of abdominal obesity. Am J Respir Crit Care Med 2009; 179: 509-16.

35. Paek YJ, Jung KS, Hwang YI, Lee KS, Lee DR, Lee JU. Association between low pulmonary function and metabolic risk factors in Korean adults: the Korean National Health and Nutrition Survey. Metabolism 2010; 59: 1300-6.

36. Clini E, Crisafulli E, Radaeli A, Malerba M. COPD and the metabolic syndrome: an intriguing association. Intern Emerg Med 2013; 8: 283-9.

37. Mekov E, Slavova Y, Tsakova A, Genova M, Kostadinov D, Minchev $D$, et al. Metabolic syndrome in hospitalized patients with chronic obstructive pulmonary disease. Peer J 2015; 3: e1068. 